\title{
A brief review: traffic conflict techniques and the challenges of the studies in Indonesia
}

\author{
Naomi Srie Kusumastutie ${ }^{1, *}$ and Pipit Rusmandani \\ ${ }^{1}$ Polytechnic of Road Transportation Safety, Tegal, Indonesia
}

\begin{abstract}
For the past 50 years, Traffic Conflict Technique (TCT) has been growing rapidly as Surrogate Safety Measure (SSM). Unfortunately, the study of TCT as a road safety analysis tool in Indonesia is still limited. This article aims to describe the developments of TCT, regarding to the use of manual observation, automated video analysis and simulations with the Surrogate Safety Assessment Model (SSAM). This article also aims to identify the challenges of TCT implementation in improving road safety in Indonesia. Thus, it is expected to inspire researchers in Indonesia to develop TCT, for example by using Unmanned Aerial Vehicle (UAV) and microsimulation in TCT studies.
\end{abstract}

\section{Background}

Surrogate Safety Measure (SSM) is a traffic event related to traffic accidents both logically and statistically [1]. Today SSM has been widely used as an answer to the limitations of traffic accident data in its use as a road safety indicator. Because traffic accidents are considered as rare events, we have to wait for a relatively long period of time before the traffic accident data is collected so that it can be analyzed in an effort to improve road safety [2]. By using SSM, the time needed in data collection is relatively shorter, because the indicators in SSM are more common than traffic accidents. Thus we do not need to wait for traffic accidents to occur in advance to be able to make prevention efforts.

Indicators that are often used in SSM such as delay, travel time, approach speed, percent stop, queue lenght, stop-bar encroachments, red violence, percent left turn, spot speed, speed distribution, decelaration distribution and the most commonly used is traffic conflict [3]. Thus, among the indicators in the SSM, traffic conflict is the most widely developed indicator to date.

Traffic conflict is an observed event when two or more road users approach each other at a distance and time that allows a collision if the movement does not change [2]. Since its introduction by Perkins and Harris [4], Traffic Conflict Techniques (TCT) has experienced rapid development. In the course of its history, various countries have developed this technique, such as the United States, Britain, Canada, Finland, Germany, France, Sweden, Austria, Denmark, and the Netherlands. Researchers from various countries in 1984 met in Copenhagen and calibrated TCT in Malmo, which became known as Malmo Study [5]. Until now various
TCT has developed following the development of technology. This shows that traffic conflict as a measure of road safety has been widely accepted and proven effective. Even traffic conflicts have also been used in developing countries. However, unfortunately, the application of TCT in the study of road safety in Indonesia is still very limited.

This review was based on internet searches related to TCT development and TCT studies in Indonesia. This article aims to provide an overview of TCT's development, from the beginning of the appearance of TCT to the development of automated video analysis and simulation with Surrogate Safety Assessment Model (SSAM). In addition this article also aims to identify the challenges of the implementation dan the development of TCT in Indonesia. Thus it is expected that it will inspire researchers to be able to develop or use TCT in an effort to improve road safety in Indonesia.

\section{The early development of traffic conflict technique}

The traffic conflict study was originally carried out by Perkins and Harris for General Motors [4]. This technique establishes six criteria for potential traffic accidents that occur at signalized intersections that are determined based on the right lane traffic movements, i.e. left turn conflict criteria, weave conflict criteria, thru on red conflict criteria, left turn on red conflict criteria, rear-end conflict criteria, and other types of traffic conflicts. Especially for thru on red conflict criteria and left turn on red conflict criteria, there are no need for a second vehicle to be

\footnotetext{
Corresponding author: naomisrie@yahoo.com
} 
involved in traffic conflicts. Some of these criteria can be seen in Figure 1.

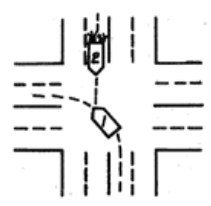

a) left turn conflict criteria

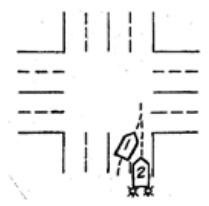

b) weave conflict criteria

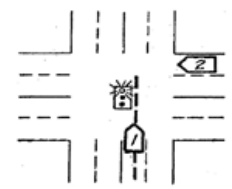

c) thru on red conflict criteria
Fig. 1. Some examples of Perkin and Harris's conflicts criteria

The same as traffic conflict techniques from Perkins and Harris [4], traffic conflict technique from the Federal Highway Administration (FHWA) [6] is also based on right lane traffic movements and has not identified conflict severity. There are six types of traffic conflicts, namely same direction conflicts, opposing left turn conflict, cross traffic conflicts, right-turn-on-red conflicts, pedestrian conflicts, and secondary conflicts. Some examples of traffic conflicts can be seen in Figure 2.

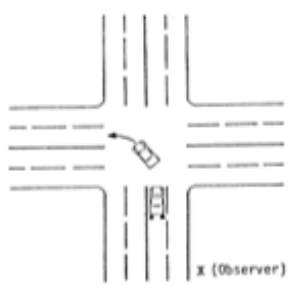

a) left turn, same direction conflict

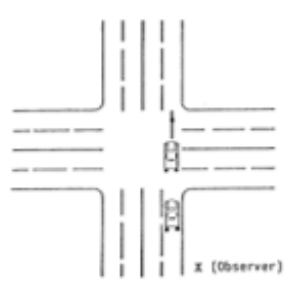

c) slow vehicle, same direction conflict

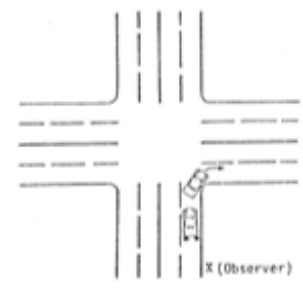

$$
\begin{aligned}
& \text { b) right turn, } \\
& \text { same direction } \\
& \text { conflict }
\end{aligned}
$$

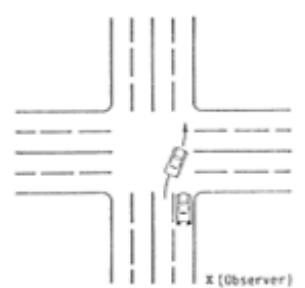

$$
\begin{aligned}
& \text { d) lane change, } \\
& \text { same direction } \\
& \text { conflict }
\end{aligned}
$$

Fig. 2. Examples of same direction conflics

Unlike Perkins and Harris [4], traffic conflict technique from FHWA [6] always involve a minimum of two vehicles. This technique also introduces the existence of secondary traffic conflicts, namely when the second vehicle carries out evasion which causes the third vehicle to be in a traffic conflict situation. In this event only one incident of secondary traffic conflict was counted. If the incident causes the vehicles behind the third vehicle to brake, this is not counted as a secondary traffic conflict.

Transport and Road Research Laboratory (TRRL) [7] developed TCT which is different from GM and FHWA. If TCT from GM and FHWA only identifies traffic conflicts based on traffic movements and has not identified the severity of traffic conflicts, TCT from
TRRL has divided traffic conflicts according to their severity. The severity of traffic conflict is determined by four factors, namely factor A (the difference in time between the commencement of evasive action and potential collisions), factor B (the severity of evasive action performed), factor $\mathrm{C}$ (the complexity of evasive action done), and factor $\mathrm{C}$ (distance between vehicles involved in traffic conflicts).

Each factor has criteria in determining the severity. For example, in factor A there are three levels of severity, namely long, moderate and short (7). Factor A is measured when the vehicle starts evading (braking or changing direction). The Observer must estimate how long it will take before a collision occurs if the evasive action is not carried out. Conditions that can be taken into consideration in assessing the severity of factor A are distance, speed, and direction of the two vehicles involved in traffic conflicts. Although the video is available as a reference for assessment, this assessment is quite susceptible to subjectivity.

Swedish TCT was developed by Lund University since the 1970s. After experiencing several changes, the latest version is the 2018 version [2]. The conflict severity in Swedish TCT is measured through two indicators, namely Time to Accident (TA) and Conflicting Speed (CS) [2]. TA is the time left for a collision when evasive action is carried out by road users, while CS is the speed of the road user during evasive action. TA measurement begins when one of the road users starts evasive action until a collision occurs if the vehicle's speed and direction do not change. CS is the speed at which TA is measured. The lower the TA value and the higher CS indicates the higher the severity of the traffic conflict that occurs [2]. TA value is determined based on Table in Figure 3.

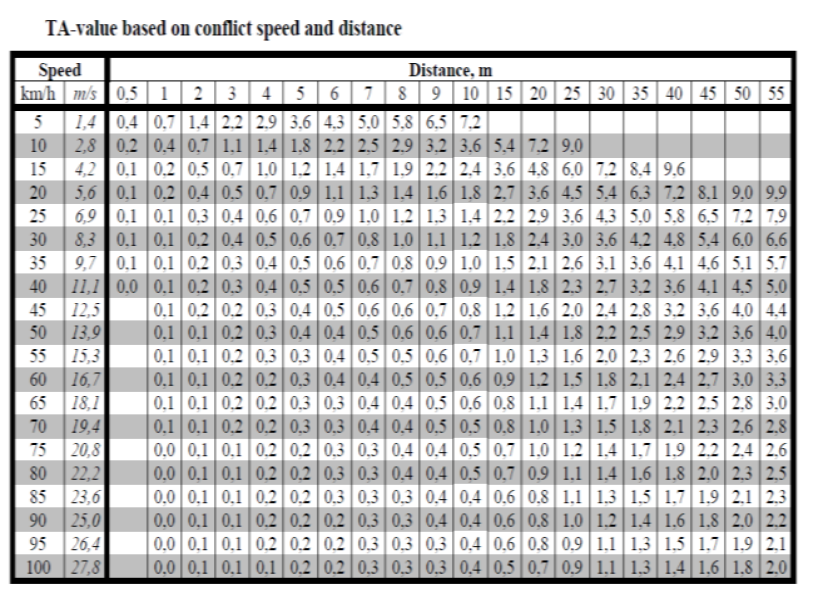

Fig. 3. TA table

After CS and TA are determined, the severity of traffic conflict can be measured. Determining the severity of traffic conflicts follows a conflict severity diagram in Figure 4 . The red line is the boundary between serious conflict and non-serious conflict. 


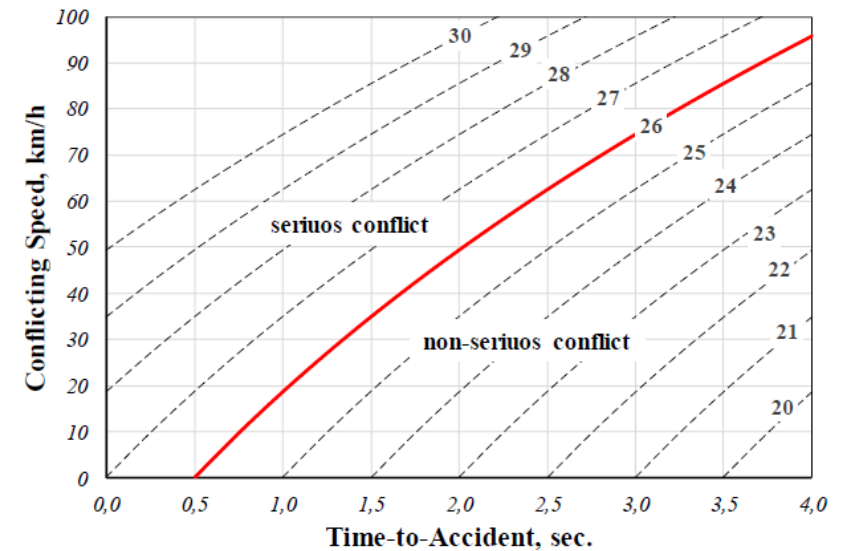

Fig. 4. Conflict severity diagram

Then there is a TCT which is used to measure pedestrian safety, namely the Pedestrian Risk Index (PRI) [8]. There are three parameters that will be measured to get the PRI value, namely $\mathrm{TTC}_{\mathrm{v}}$ (Time to Collision of Vehicle), TTC $_{p}$ (Time to Collision of Pedestrian), and Vehicle time to stopping $\left(\mathrm{T}_{\mathrm{s}}\right)$.

Furthermore, these three parameters are used to explain three phases in traffic conflict, as follows:

1. When $\mathrm{TTC}_{\mathrm{v}}>\mathrm{T}_{\mathrm{s}}$ means the vehicle can stop before the conflict area.

2. When $\mathrm{TTC}_{\mathrm{v}}<\mathrm{TTC}_{\mathrm{p}}$ means pedestrians arrive in the conflict area after the vehicle passes.

3. When $\mathrm{TTC}_{\mathrm{v}}<\mathrm{T}_{\mathrm{s}}$ means the vehicle cannot stop before reaching the conflict area.

4. When $\mathrm{TTC}_{\mathrm{p}}<\mathrm{TTC}_{\mathrm{v}}$ means pedestrians are involved in a conflict with the vehicle.

The conflict phase is defined as TTZ duration (Time To Zebra duration) in the $\mathrm{TTC}_{\mathrm{p}}<\mathrm{TTC}_{\mathrm{v}}<\mathrm{T}_{\mathrm{s}}$ interval. Traffic conflict parameters in PRI as presented in Figure 5.

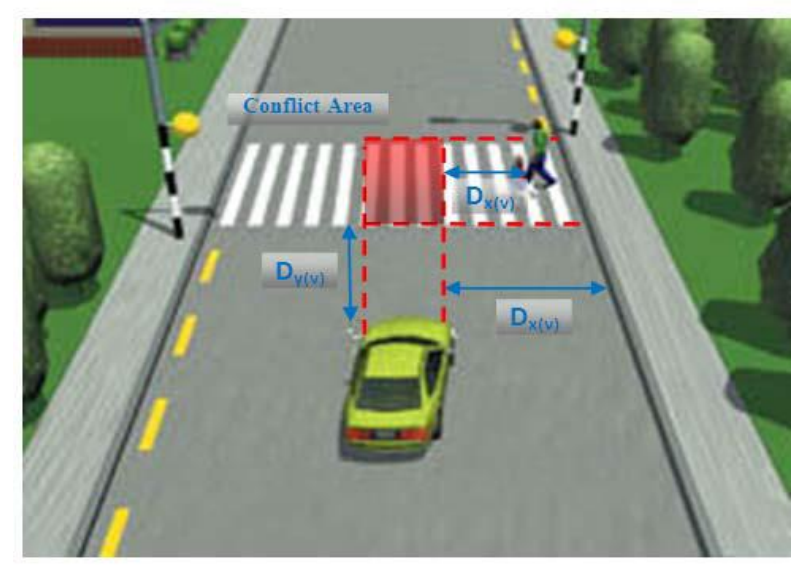

Fig. 5. Parameters in Pedestrian risk index

At first, data collection of traffic conflicts was carried out by field observation. The observers were given traning before conducting a survey to get a common perception about the measurement procedures, in this case the determination of the distance and speed of the vehicle. To reduce subjectivity, two observers are usually used.
Field observation is considered quite difficult because it requires high concentration. In addition, observers also only have one chance to see and assess a traffic conflict event [2]. When an event has passed, it cannot be repeated to ensure measurement.

To overcome this, a video camera is used in field observations in traffic conflict data collection [2]. Through video, an event can be repeated to ensure measurement. In addition, the use of video cameras also has other advantages, such as allowing observation to take place in a longer period of time, can be used in locations that do not allow direct observation, have minimal influence on traffic, and allows studying complex situations in detail.

\section{The latest development of TCT}

In the course of time, the use of video cameras in observing traffic conflicts is no longer sufficient, related to efficiency, standardization of results, and measurement accuracy $[2,9]$. The answer to this problem is the use of automated video processing. By using automated video processing, traffic conflict analysis is no longer carried out by observers but is automatically carried out by software through highly complex video processing algorithms. The procedure for analyzing traffic conflicts with automated video processing is shown in Figure 6

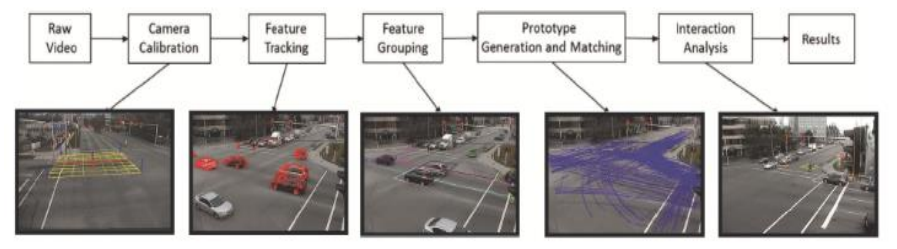

Fig. 6. Procedure for analyzing traffic conflicts with automated video processing

The latest issue of TCT is the use of microsimulation in traffic conflict analysis. One of them that has been widely used is the Surrogate Safety Assessment Model (SSAM) developed by FHWA [3]. This software can be downloaded for free. SSAM works by processing trajectory data that is inputted from a file with the .trj extension. This trajectory file is generated by traffic simulation software, namely AIMSUM, paramics, VISSIM, and TEXAS. With this data, SSAM will calculate several indicators, namely minimum time to collision (TTC), minimum post-encroachment time (PET), initial deceleration rate (DR), maximum speed (MaxS), maximum relative speed difference (DeltaS), location of the conflict event (CLSP, CLEP), and maximum DeltaV (MaxDeltaV). Measurement results can be imported into Ms. format Excel can then be processed further. SSAM workflow can be seen in Figure 7.

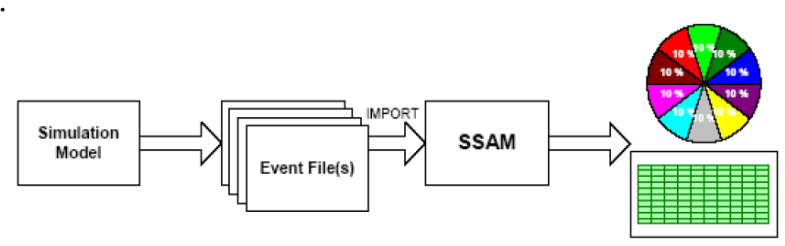

Fig. 7. SSAM workflow 
The latest version of this software is SSAM v3.0. [10] In this version there are additional features, such as illustrations of traffic conflict depictions (bar graphs, heat maps, and contour maps), the ability to enlarge images on traffic conflict maps, and additional indicators (multiple PET or mPET, multiple TTC or mTTC, and possible circumvention efforts or $\mathrm{P}$ (UAE).

Studies related to SSAM validation have been carried out by a number of researchers. For this reason, they compared the conflict data of SSAM simulation results with traffic accident data as well as traffic conflict data obtained from field observations [3, 11-13]. The result of the validity testing above is that the use of SSAM still has several limitations, but it is promising to be developed further in road safety measurement.

\section{Traffic conflict studies in Indonesia}

When compared with developed countries, the study of application and development of TCT in Indonesia is still far behind. Based on online searching, scientific publications related to TCT conducted in Indonesia are only found in limited numbers [14-23]. In the search actually found also some Indonesian researchers who conducted research related to traffic conflict on abroad, for example, conducted by Malkhamah et al. [24] or Suwarto and Basuki [25]. Because this article focuses on traffic conflict studies conducted in Indonesia, those studies are not in the discussion of this article.

Lawalata and Agah [14] note that the oldest TCT study in Indonesia that can be found is a study conducted by Legowo in 1990. Legowo uses TCT from TRLL in his study to evaluate the level of safety in two signalized intersections and two unsigned intersections in Bandung City. In addition to the study, Lawalata and Agah [14] also noted another TCT study in Indonesia which also used TCT from TRLL, i.e TCT study to analyze illegal officers' functions in maintaining the smoothness and safety of traffic in unsigned T-intersections in Bandung City, measuring effectiveness of handling traffic conflicts at Simpang Y in Cimahi, and measuring the effectiveness of Special Stopping Space (SSS) to reduce traffic conflicts in a number of signalized intersections in the cities of Bandung and Denpasar.

Because of the simplicity, Swedish TCT is becoming the most popular technique used in Indonesia [15-18]. Besides being used to evaluate the level of safety at unsignalized intersections in Sukoharjo [15] and in Yogyakarta [16], Swedish TCT is also used in traffic conflict studies between pedestrians and bus in Jakarta [17], and at intersections with canalization and U-turn in Jakarta [18].

In addition to the two types of TCT, several traffic conflict studies were conducted in Indonesia using another TCT. Kusumastutie and Malkhamah (19-20) used the Pedestrian Risk Index (PRI) to analyze the safety level of crossing students in Sukoharjo, Tanan [21] using TCT from FHWA to measure the effectiveness of handling an intersection in Cimahi, and Mulyadi and Amelia [22] using TCT from Bagulay to measure the effectiveness of the implementation of the red motorcycle box in Bandung.

The study of traffic conflicts in Indonesia that was described above, uses a field observation procedure conducted by a number of observers who have received previous training. In addition, video cameras were also used to record traffic conflicts. To improve reliability, traffic conflicts were analyzed by two observers $[15,19$ 20], so the results can be compared. In the studies recorded by Lawalata and Agah [14] conflicts per 1000 vehicles were used as indicators in evaluation and analysis.

In the study of traffic conflicts in Indonesia, TCT was used as a tool to evaluate road safety at the study location. Furthermore, the results of the analysis are used to formulate recommendations to improve road safety. In studies conducted by Tanan [21] and Mulyadi and Amelia [22], TCT was used to measure the effectiveness of treatments that had been implemented at the study site.

When viewed from the affiliation of researchers in the study of traffic conflicts in Indonesia above, it can be seen that at first the study of traffic conflicts in Indonesia was carried out by researchers affiliated with Research and Development Center for Road and Bridges (Pusjatan) [14, 21-22]. Furthermore, there are also researchers from the University of Indonesia [17-18], Gadjah Mada University [19-20, 23], Diponegoro University [24], Islam Indonesia University [16], and the Polytechnic of Road Transportation Safety (PKTJ) [15, 19-20]. It can be seen that these institutions are prominent research institutions and higher education in the field of transportation, especially those that have attention to the field of road safety in Indonesia.

\section{The challenges for traffic conflict studies in Indonesia}

The study of traffic conflict has been carried out in Indonesia since 1990. This shows that TCT has been responded well by Indonesian researchers even from the beginning of its development. Unfortunately, the traffic conflict study in Indonesia was then vacuum for quite a long time. Based on internet searches, scientific publications on traffic conflict studies in Indonesia existed in 2001 [17]. After that, scientific publications of traffic conflict study in Indonesia began to emerge, which was conducted by researchers affiliated with leading research and higher education institutions in Indonesia.

Almost all traffic conflict studies in Indonesia use TRRL conflict model and Swedish TCT. The data collection are carried out using human observers. Standard field observation procedures are also always fulfilled, such as training for observers, preliminary surveys, use of video cameras and interobserver reliability.

There are at least two limitations to the study of traffic conflicts in Indonesia mentioned above. The first is related to the use of technology. It is related to the use of video cameras to record traffic events at the study site. In this case the observer had the opportunity to replay the video recordings to ensure the measurement of traffic 
conflicts. However, the estimation of the distance and speed of vehicles is still a problem in itself. Video cameras that should be placed at an altitude to obtain adequate recording area coverage can often only be placed using a tripod at approximately 1 meter due to the absence of tall buildings or the like at the study site. Thus the recordings produced are often not optimal so they encounter various obstacles in determining accurate distance and speed, for example vehicles are blocked by other vehicles or limited area of view.

This obstacle was tried to overcome through conducting training for observers and preliminary surveys before the main survey was carried out. This effort is intended to get agreement between observers. One of them is about determining the strategy in measuring the distance and speed of the vehicle. So that traffic conflicts observation can be quite draining time and energy, especially for beginners.

The use of automated video processing in traffic conflict studies in Indonesia is currently still constrained by the unavailability of this technology. This high-cost technology may also not be available in the near future. For this reason, the use of human observers is still not replaced. To overcome the obstacles in estimating vehicle distance and speed, Indonesian researchers can innovate by using Unmanned Aerial Vehicle (UAV) in traffic conflict observation.

UAVs are aircraft that are controlled by pilots on land or by an electronic system [25]. It has been used in various fields, both for military and civilian purposes. As a traffic data collection tool, UAV was used in research conducted by Barmpounakis et al [25], Coifman et al [26], and Salvo et al [27]. The use of UAVs in traffic surveys has the advantage of providing cost-effective "eye in the sky" solutions [25]. In addition, UAV also has no effect on driver behavior [27].

The utilization of UAV in traffic safety research in Indonesia has been carried out by Lovita, et al [28], namely to collect vehicle gaps and vehicle lags data at intersections. The results of this study indicate that recording by UAV is accurate in detecting vehicle gaps and vehicle laps at intersections. Thus, it is very possible to use UAVs in traffic conflict studies.

Secondly, TCT is only used to evaluate road safety in existing conditions. In this case, traffic conflict is used as an indicator of risk assessment and is used to identify road safety problems in that location. Then countermeasures are proposed based on the analysis of traffic conflicts, which are expected to improve road safety. However, almost all traffic conflict studies in Indonesia only proposed countermeasures. The studies did not remeasure traffic conflicts after countermeasures are given. Information about the impact of countermeasures provided was only obtained in the research conducted by Tanan [21] and Mulyadi and Amelia [22]. Even then it is done after handling is really implemented, so that it has consequences on time and cost.

In this case it is recommended to use microsimulation modelling. Besides being able to evaluate traffic safety on existing conditions, microsimulation can also evaluate the impact of the countermeasures before they are actually implemented at the study site. By using simulation, we can use several alternative treatments in various experimental scenarios. With this, it is expected to minimize the consequences of time and costs also risks that might arise with the implementation of the countermeasures at the study site.

VISSIM has been owned by several higher education institutions and SSAM can be obtained free of charge so as to facilitate the use of microsimulation in traffic conflict studies in Indonesia. The study can begin with SSAM validation to see the suitability of its use with mixed traffic conditions and typical road user behavior in Indonesia. Through the synergy of UAV and microsimulation utilization, this can be the starting point for TCT development in Indonesia.

\section{Conclusion}

Until now, traffic conflicts have been trusted as SSM used in road safety analysis in various contexts. TCT has undergone a long developmental journey, from the manual observations to the latest developments in the simulations with the Surrogate Safety Assessment Model (SSAM). With the presence of Indonesian researchers from a variety of leading institutions that pay attention to TCT, the challenges of implementing and developing TCT in Indonesia are wide open. The closest is to using UAV as a traffic conflict recording tool and simulation using SSAM.

\section{References}

1. J. Ambros, Traffic Conflict Technique As A Complementary Method Of Road Safety Management, in XI International Symposium "Road Accident Prevention 2012" (2012).

2. A. Laureshyn and A. Várhelyi, The Swedish Traffic Conflict Technique Observer's Manual, Lund University, Lund (2018).

3. G. Gettman, L. Pu, T. Sayed, and S. Shelby, Surrogate Safety Assessment Model and Validation: Final Report, U.S. Department of Transportation Federal Highway Administration (2008).

4. S. R. Perkins and J. I. Harris, Criteria for Traffic Conflict Characteristics Signalized Intersections, General Motor Corporation, Michigan (1967).

5. A. Asmussen, International Calibration Study of Traffic Conflict Techniques, Springer (1984).

6. M.R. Parker and C.V. Zegeer, Traffic Conflict Techniques for Safety and Operations Observer Manual, U.S Departement of Transportation, Federal Highway Administration, Virginia (1989).

7. Transport and Road Research Laboratory, Highway Safety The Traffic Conflict Technique, The Institution of Highways and Transportation, London (1987).

8. S. Cafiso, A. G. Garcia, R. Cavarra, R., and M. A. R. Rojas, Before and After Study of Crosswalk Using a Pedestrian Risk Index, 16th June 2011. 
[Online].Available:http://www.amonline.trb.org/1 $2 \mathrm{k} 96 \mathrm{v} / 12 \mathrm{k} 96 \mathrm{v}$.

9. C. Pin, T. Sayed, and M. H. Zaki, Assessing Safety Improvements to Pedestrian Crossings Using Automated Conflict Analysis, Journal of the Transportation Research Board, 2514, 58-67, (2015).

10. FHWA, Open Source Surrogate Safety Assessment Model, 2017 Enhancement and Update: SSAM v3.0, Publication No. FHWA-HRT-17-027 (2016).

11. R. Fan, H. Yu, P. Liu, and W. Wang, Using VISSIM Simulation Model and Surrogate Safety Assessment Model for Estimating Field Measured Traffic Conflicts at Freeway Merge Areas, IET Intelligent Transport Systems, 7, 68-77 (2013).

12. L. Vasconcelos, L. Neto, L. M. Seco and A. B. Silva, Validation of the Surrogate Safety Assessment Model for Assessment of Intersection Safety, Journal of the Transportation Research Board, 2432, 1-9 (2014).

13. M. Essa, and T. Sayed, Transferability of Calibrated Microsimulation Model Parameters for Safety Assessment Using Simulated Conflicts, Accident Analysis and Prevention, 84,41-53 (2015).

14. G. M. Lawalata and H. R. Agah, Traffic Conflict Analysis As A Road Safety Diagnostic Tool For Urban Road Facilities, International Journal of Technology, 2,112-121 (2011).

15. N. S. Kusumastutie, Penerapan The Swedish Traffic Conflict Technique pada Audit Keselamatan Jalan di Proliman Peteng Sukoharjo, Jurnal Keselamatan Transportasi Jalan, 2, 2, 40-48 (2014).

16. P. J. Romadhona and S. Ramdhani, Pengaruh Kecepatan Kendaraan Terhadap Keselamatan Pengguna Kendaraan Bermotor pada Simpang Tak Bersinyal, Rekayasa Sipil, 1, 31-40 (2017).

17. M. L. Siregar, TCT (Swedish Traffic Conflict Techniques) Method for Safety Based Evaluation of The Provision of With Flow Bus Lane on Fast Lane, Jurnal Teknologi, 1, 1, XV, 17-25 (2001).

18. M. L. Siregar, H. R. Agah, and F. Hidayatullah, Near-Miss Accident Analysis For Traffic Safety Improvement At A 'Channelized' Junction With UTurn, Int. J. of Safety and Security Eng., 8, 1, 3138 (2018).

19. N. S. Kusumastutie and S. Malkhamah, Analisis Keselamatan Penyeberang Menggunakan Pedestrian Risk Index (PRI) Studi Kasus pada Siswa Penyeberang di SMPN 4 Sukoharjo, in The 17th FSTPT International Symposium, Jember, (2014).

20. N. S. Kusumastutie and S. Malkhamah, Pengaruh Perilaku Menyeberang Terhadap Keterlibatan Dalam Konflik Lalu Lintas," Jurnal Keselamatan Transportasi Jalan, 1, 23-32 (2013).
21. N. Tanan, Penanganan Konflik Lalu Lintas di Persimpangan Gatot Subroto-Gedung Empat Cimahi, Jurnal Jalan dan Jembatan, 25, 3, 291-313 (2008).

22. A. M. Mulyadi and S. Amalia, Influence Of Red Motorcycle Box To The Traffic Conflict And Traffic Flow At The Ahmad Yani-Laswi Signalized Intersection," in 16th Road Safety on Four Continent Conference, Beijing, China (2013).

23. S. Malkhamah, M. Tight, and F. Montgomery, The Development of an Automatic Method of Safety Monitoring at Pelican Crossing, Accident Analysis and Prevention, 37, 938-946 (2005).

24. F. Suwarto and K. H. Basuki, The Application of Traffic Conflict Technique as a Road Safety Evaluation Method: a Case Study of Hasselt Intersection, Applied Mechanics and Material, 845, 394-403, (2016).

25. E. N. Barmpounakis, E. I. Vlahogianni, and J. C. Golias, Unmanned Aerial Aircraft Systems For Transportation Engineering: Current Practice Dan Future Challenges, International Journal of Transportation Science and Technology, 5, 111122, (2016).

26. B. Coifman, M. McCord, R. G. Mishalani, and M. Iswalt, Y. Ji, Roadway Traffic Monitoring From An Unmanned Aerial Vehicle, IEE ProceedingsIntelligent Transport Systems, 153, 1, 11-20, (2006).

27. G. Salvo, L. Caruso, and A. Scordo, Urban Traffic Analysis Through An UAV, Procedia-Social and Behavioral Sciences, 111, 1083 - 1091, ( 2014 ).

28. M. Lovita, Yosritzal, and Purnawan, (2017) Pemanfaatan Drone Pada Penelitian Keselamatan Lalu Lintas di Persimpangan, in Prosiding 4th Andalas Civil Engineering (ACE) Conference, Padang, Indonesia, 527-532 (2017). 